(CASE REPORT)

\title{
Acute respiratory failure in ARDS: Is it "Typical" Covid-19?
}

\author{
Fatin R Polat ${ }^{1,}{ }^{*}$, Ilhan Bali ${ }^{1}$, Yasin Duran ${ }^{1}$, Ihsan Gunduz ${ }^{2}$ and Kıvanc Tas ${ }^{1}$ \\ ${ }^{1}$ Namık Kemal University Medical Faculty, Department of Surgery, Tekirdag, Turkey. \\ 2 Tekirdag State Hospital, Departmeny of gastroenterologic surgery. Tekirdag Turkey.
}

Publication history: Received on 24 May 2020; revised on 10 June 2020; accepted on 11 June 2020

Article DOI: https://doi.org/10.30574/wjarr.2020.6.3.0171

\begin{abstract}
Coronavirus disease (Covid-19) is a potentially infectious and fatal disease that is caused severe acute respiratory syndrome. A case, who was formed postoperatively, of acute respiratory distress syndrome (suspected Covid-19) has been presented and relevant literature reviewed. And, Surgeons' need for covid-19 guidance was discussed.
\end{abstract}

Keywords: ARDS; Covid-19 and Surgery

\section{Introduction}

Acute respiratory distress syndrome (ARDS) is a life-threatening lung injury that allows fluid to leak into the lungs. Breathing becomes difficult and oxygen cannot get into the body. Most people who get ARDS are already at the hospital for trauma, post-surgery or illness.

Coronavirus disease (Covid-19) is caused by SARS-COV2 and represents the causative agent of a potentially fatal disease that is of great global public health concern [1]. Covid-19 is caused severe acute respiratory syndrome.

We report a case who suspected Covid-19, postoperative first day developed rapidly worsening respiratory failure and ARDS. And, Surgeons' need for covid-19 guidance was discussed.

\section{Case presentation}

A 25-year-old man presented acutely to the general surgery with an abdominal pain. X-Ray examination showed free air under diaphragm (Figure I,II). Initial laboratory investigations, consisting biochemistry tests and hemogram, were in normal limits. Fever was 38,2 ${ }^{\circ} \mathrm{C}$, pulse was 120 / min. Emergency surgery planned and underwent surgery for stomach perforation. Postoperative first day developed rapidly worsening respiratory failure and high fever $\left(39-39,5^{\circ} \mathrm{C}\right)$ at the patient (Figure III). We carried the patient Intensive care unit (ICU) because of ARDS (suspected Covid-19). Chest radiograph (X-Ray) demonstrated bilateral alveolar shadows and high resolution computerized tomography (CT) thorax showed crazy paving pattern (Figure IV,V). Firstly we used the rapid diagnostic test, result was negative. Second day we used real-time reverse transcription (RT-PCR) test result was negative, too. But clinical evidence with results of chest CT was coherented with Covid-19. At ICU the patient was only supported with low molecular weight heparins and low dose oxygen therapy. On post-operative 20 days review the patient was well and discharge without no any complication. (Figure VI).

\footnotetext{
* Corresponding author: Fatin R Polat
} 


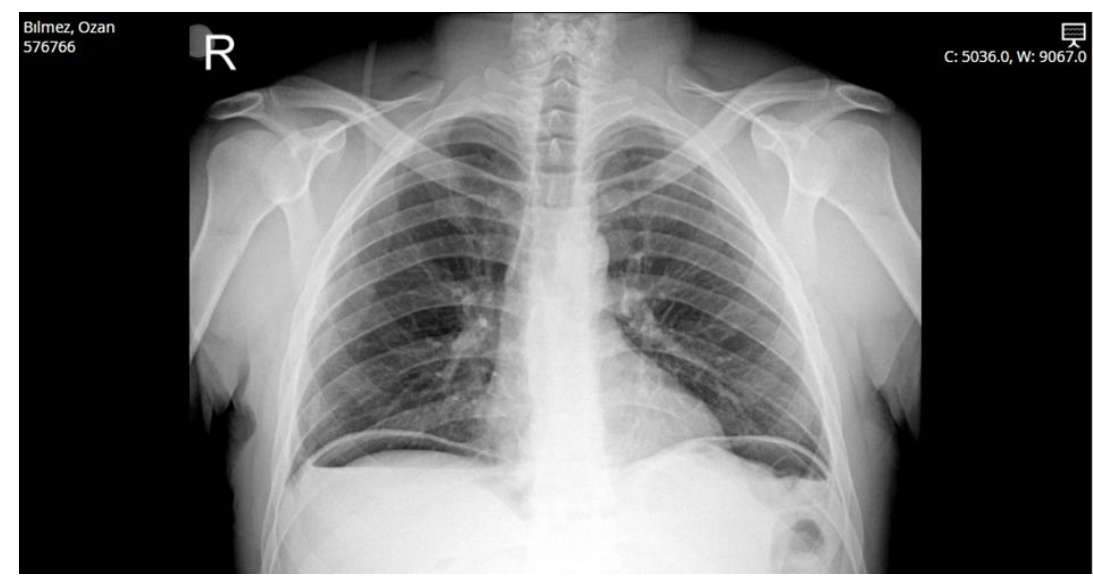

Figure 1 Free air under the diaphragm

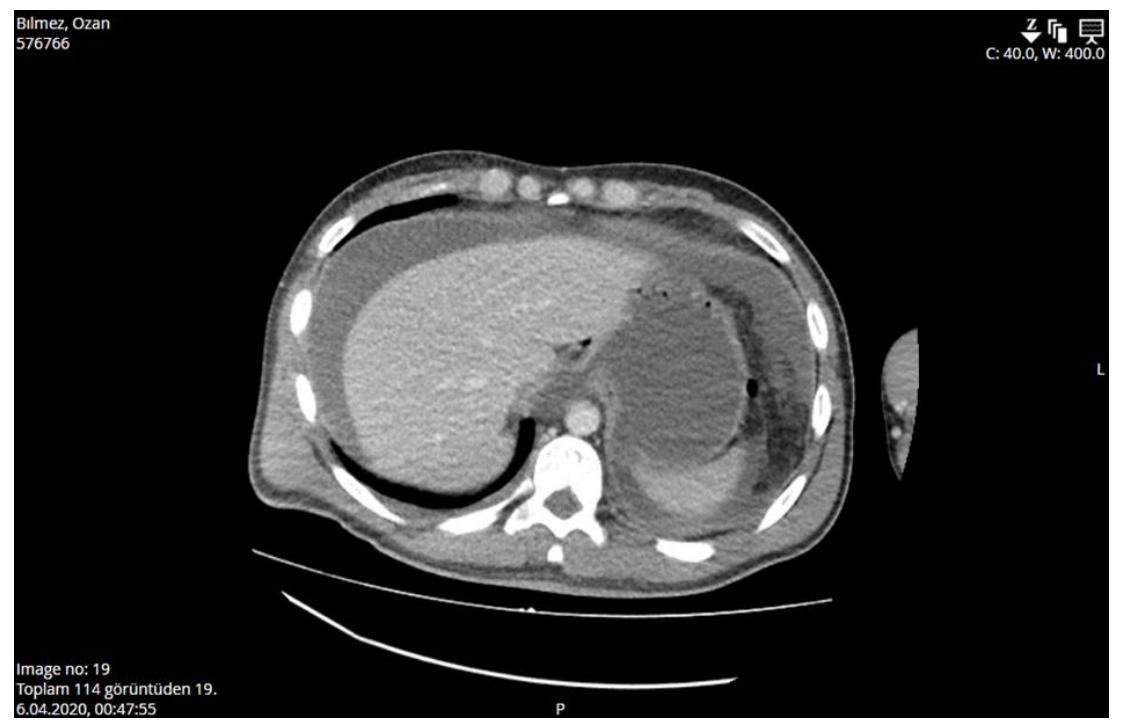

Figure 2 Fluid in the abdomen

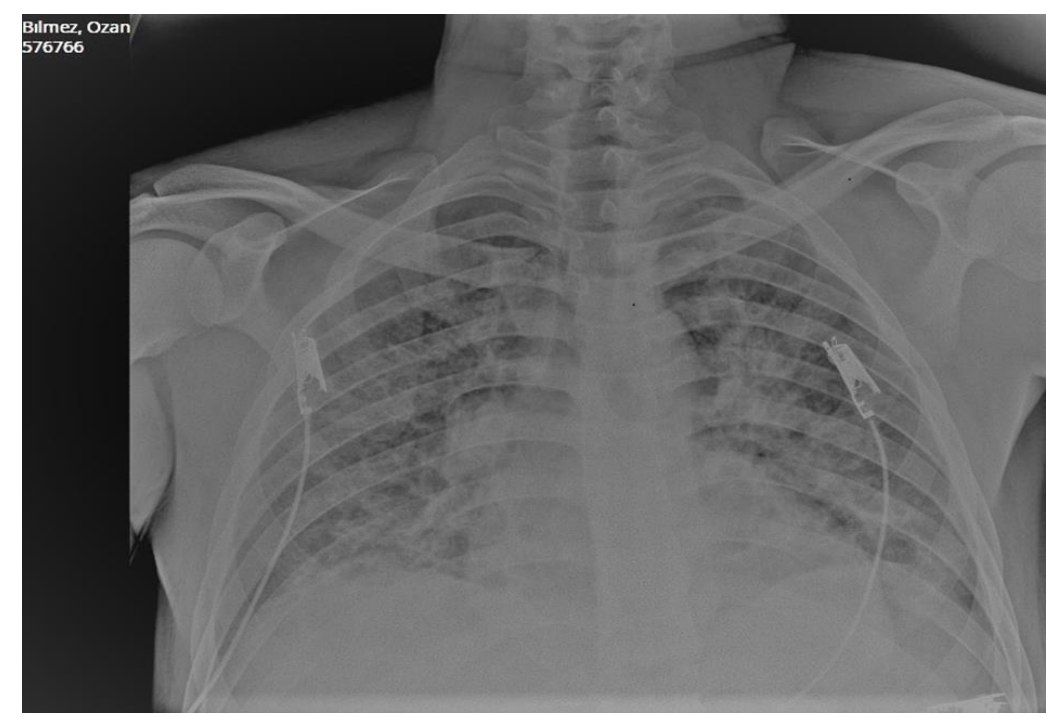

Figure 3 ARDS 


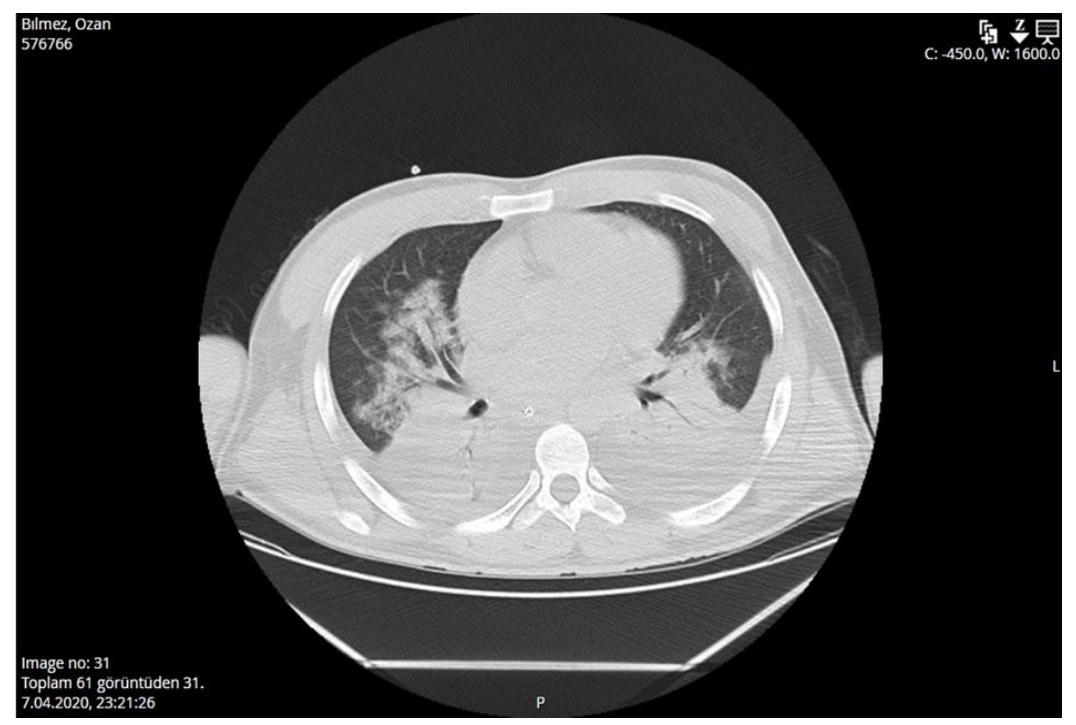

Figure 4 Typically Covid-19 image in the CT

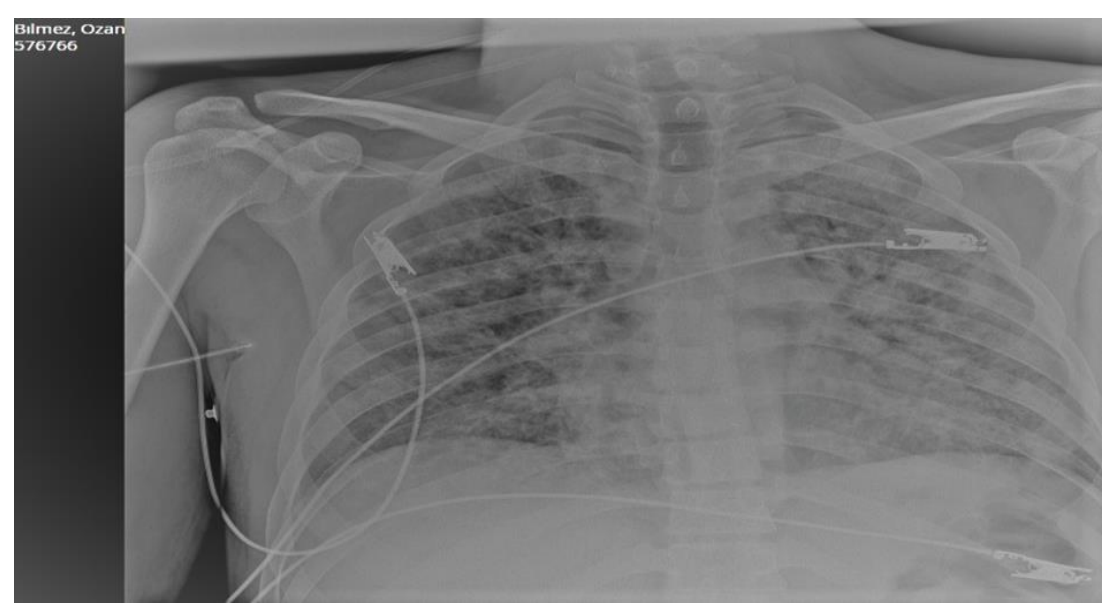

Figure 5 ARDS

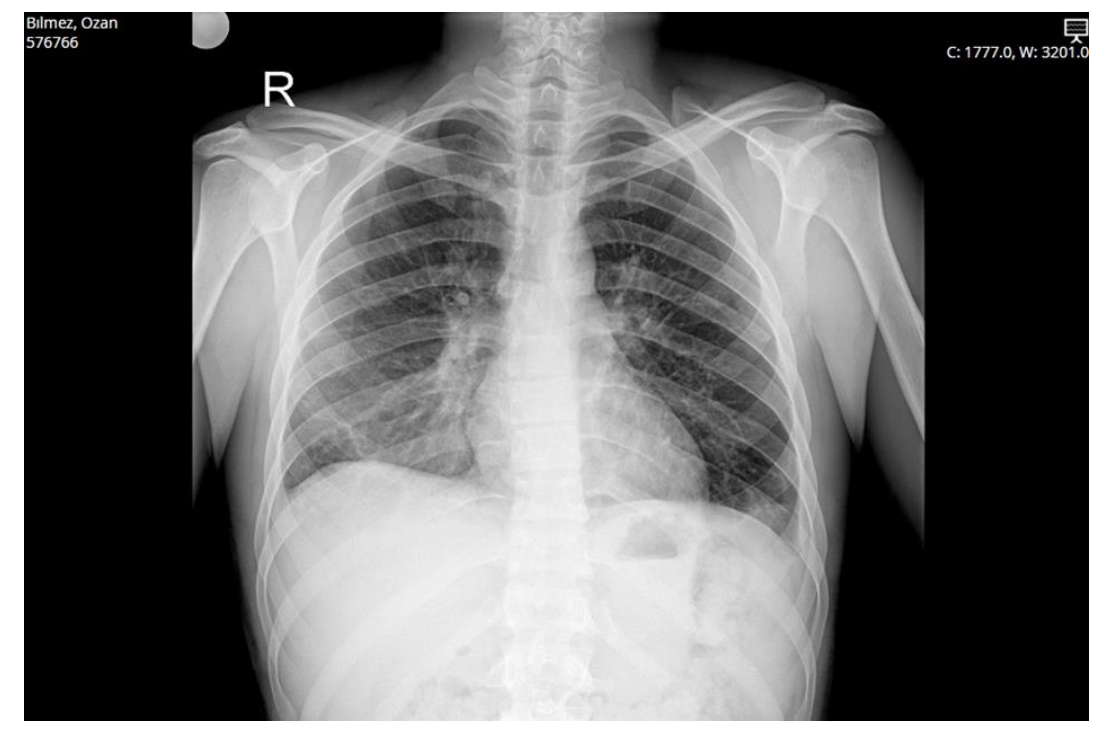

Figure 6 Image of the normal lungs after treatment 


\section{Discussion}

A novel zoonotic coronavirus outbreak is spreading both in Turkey and all over the World. This pandemic disease has now been defined as novel coronavirus disease, and is sustained by severe acute respiratory syndrome coronavirus [2].

As the current gold standard for the etiological diagnosis of SARS-CoV-2 infection is RT-PCR on respiratory tract specimens, the diagnostic accuracy of this technique shall be considered a foremost prerequisite ${ }^{2}$. RT-PCR is currently the most reliable diagnostic method for Covid-19 around the world. Chung et al. [3] reported that chest CT may be negative for viral pneumonia of Covid-19 at initial presentation (3/21 patients). CT lacks complete sensitivity and cannot alone reliably fully exclude this disease, particularly early in the infection [3]. On the other side; recently, Xie et al. [4] reported 5/167 (3\%) patients who had negative RT-PCR for Covid-19 at initial presentation despite chest CT findings typical of viral pneumonia. Fang and al. [5] found, the sensitivity of chest CT was greater than that of RT-PCR (98\% vs 71\%, respectively). Unfortunately, the exact results cannot be obtained with either method.

As the clinical spectrum of Covid-19 ranges widely from mild illness to ARDS with a high risk of mortality, there is a need for more research to identify early markers of disease severity [6]. Currently, there is not any specific effective antiviral treatment for Covid-19. In those patients; Hemodynamics need be closely monitored and anti-venous thromboembolism and oxygen support is the basis of treatment. The most frequently used agents in Turkey including chloroquine, hydroxychloroquine, lopinavir/ritonavir, favipiravir and remdesivir [7]. NK University Covid committee accepted the patient as a suspected covid patient while we suspected ARDS caused by surgery. We did not used any this agents at the case, only supported with low molecular weight heparins and low doze oxygen terapy. We are still not sure whether the patient was a Covid-19 or not.

Standard supportive care for ARDS should now include a protective ventilatory strategy with low tidal volume ventilation by the protocol developed by the National Institutes of Health ARDS Network [8]. There is no evidence that low volume ventilation is beneficial in patients where hypercapnia is potentially harmful [9].

For the request from frontline clinicians and public health professionals of 2019-nCoV infected pneumonia management, an evidence-based guideline urgently needs to be developed [10].

It has been noted that gastrointestinal symptoms including nausea and diarrhea are also present in a significant subset of COVID-19 patients in addition to documented presence and persistence of virus in feces of patients who have appeared to be asymptomatic or who have otherwise appeared to recovered. Lamers et al demonstrated that the virus infects human gut enterocytes [11]. In this case, the surgical team is perform surgery during emergency by taking high risks. As a result; surgeons urgently need guidance on how to deliver surgical services safely and effectively during the Covid-19 pandemic.

\section{Conclusion}

Surgeons will be asked to serve and lead during this pandemic. The guidelines which is prepared by associations must be used during emergency surgical cases treatment.

\section{Compliance with ethical standards}

\section{Acknowledgments}

The authors were grateful to all people involved in this research.

\section{Disclosure of conflict of interest}

The authors has no conflict of interest to declare.

\section{Statement of informed consent}

Informed consent was obtained from all individual participants included in the study. 


\section{References}

[1] Rothan HA and Byrareddy SN. (2020).The epidemiology and pathogenesis of coronavirus disease (COVID-19) outbreak. J Autoimmun, 109, 102433.

[2] Lippi G, Simundic AM and Plebani M. (2019). Potential preanalytical and analytical vulnerabilities in the laboratory diagnosis of coronavirus disease (COVID-19).

[3] Chung M, Bernheim A, Mei X et al. (2019). CT Imaging Features of 2019 Novel Coronavirus (2019-nCoV). Radiology, undefined (undefined), 200230.

[4] Xie X, Zhong Z, Zhao W, Zheng C, Wang F and Liu J. (2020). Chest CT for typical 2019-nCoV pneumonia: relationship to negative RT-PCR testing. Radiology.

[5] Fang Y, Zhang H, Xie J, et al. (2020). Sensitivity of Chest CT for COVID-19: Comparison to RT-PCR [published online ahead of print, 2020 Feb 19]. Radiology, 200432.

[6] Goh KJ, Choong MC, Cheong EH, et al. (2020). Rapid Progression to Acute Respiratory Distress Syndrome: Review of Current Understanding of Critical Illness from COVID-19 Infection. Ann Acad Med Singapore, 49(3), 108-118.

[7] Şimşek Yavuz S and Ünal S. (2020). Antiviral treatment of COVID-19. Turk J Med Sci, 50(SI-1), 611-619.

[8] Brower RG, Ware LB, Berthiaume Y and Matthay MA. (2001).Treatment of ARDS. Chest, 120(4), 1347-1367.

[9] Petrucci N and Iacovelli W. (2003). Ventilation with lower tidal volumes versus traditional tidal volumes in adults for acute lung injury and acute respiratory distress syndrome. Cochrane Database Syst Rev, (3), CD003844.

[10] Jin YH, Cai L, Cheng ZS, et al. (2020). A rapid advice guideline for the diagnosis and treatment of 2019 novel coronavirus (2019-nCoV) infected pneumonia (standard version). Mil Med Res, 7(1), 4.

[11] Mart ML, Joep B, Jelte VD, et. (2020). Al. SARS-CoV-2 productively infects human gut enterocytes.

\section{How to cite this article}

Polat FR, Bali I, Duran Y, Gunduz I and Tas K. (2020). Acute respiratory failure in ARDS: Is it "Typical" Covid-19? World Journal of Advanced Research and Reviews, 6(3), 30-34. 